\title{
Phenotypes of Apolipoprotein B and Apolipoprotein E after Liver Transplantation
}

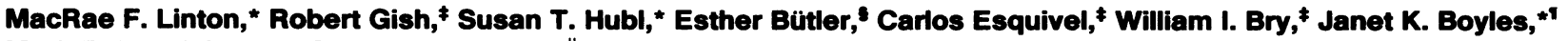 \\ Mark R. Wardell," and Stephen G. Young ${ }^{\star \|}$ \\ *Gladstone Foundation Laboratories for Cardiovascular Disease, Cardiovascular Research Institute, Departments of "Medicine and \\ 'Pathology, University of California, San Francisco, California 94140-0608; ${ }^{\ddagger}$ Liver Unit, Pacific Presbyterian Medical Center, San \\ Francisco, California 94115; and ${ }^{\S}$ Central Laboratory, Blood Transfusion Service of the Swiss Red Cross, CH-3000 Berne 22, Switzerland
}

\begin{abstract}
Apolipoprotein (apo) E and the two B apolipoproteins, apoB48 and apoB100, are important proteins in human lipoprotein metabolism. Commonly occurring polymorphisms in the genes for apoE and apoB result in amino acid substitutions that produce readily detectable phenotypic differences in these proteins. We studied changes in apoE and apoB phenotypes before and after liver transplantation to gain new insights into apolipoprotein physiology. In all 29 patients that we studied, the postoperative serum apoE phenotype of the recipient, as assessed by isoelectric focusing, converted virtually completely to that of the donor, providing evidence that $>90 \%$ of the apoE in the plasma is synthesized by the liver. In contrast, the cerebrospinal fluid apoE phenotype did not change to the donor's phenotype after liver transplantation, indicating that most of the apoE in CSF cannot be derived from the plasma pool and therefore must be synthesized locally. The apoB100 phenotype (assessed with immunoassays using monoclonal antibody MB19, an antibody that detects a two-allele polymorphism in apoB) invariably converted to the phenotype of the donor. In four normolipidemic patients, we determined the MB19 phenotype of both the apoB100 and apoB48 in the "chylomicron fraction" isolated from plasma $3 \mathrm{~h}$ after a fat-rich meal. Interestingly, the apoB100 in the chylomicron fraction invariably had the phenotype of the donor, indicating that the vast majority of the large, triglyceride-rich apoB100-containing lipoproteins that appear in the plasma after a fat-rich meal are actually VLDL of hepatic origin. The MB19 phenotype of the apoB48 in the plasma chylomicron fraction did not change after liver transplantation, indicating that almost all of the apoB48 in plasma chylomicrons is derived from the intestine. These results were consistent with our immunocytochemical studies on intestinal biopsy specimens of organ donors; using apoB-specific monoclonal antibodies, we found evidence for apoB48, but not apoB100, in donor intestinal biopsy specimens. (J. Clin. Invest. 1991. 88:270-281.) Key words: lipoproteins • cholesterol • genetic polymorphism $\bullet$ monoclonal antibody
\end{abstract}

Address correspondence to M. Linton, Gladstone Foundation Laboratories, P.O. Box 40608, San Francisco, CA 94140-0608.

S. Hubl's current address is Department of Biochemistry, University of California, Berkeley, CA 94720.

Received for publication 26 October 1990 and in revised form 22 February 1991.

J. Clin. Invest.

(C) The American Society for Clinical Investigation, Inc.

0021-9738/91/07/0270/12 \$2.00

Volume 88, July 1991, 270-281

\section{Introduction}

Orthotopic liver transplantation-the complete removal of a diseased liver and the implantation of a normal liver from a donor-has become a common treatment for end-stage parenchymal liver disease and biliary tract disease (1). Implantation of the donor liver requires creating the appropriate surgical anastomoses for the biliary duct, the portal vein, the inferior vena cava, and the hepatic artery (1). Liver transplantation has also been used to treat a large variety of inborn errors of metabolism (1), including deficiencies of a hepatic membrane receptor, an intracellular enzyme, or a secreted protein. Recently, a familial hypercholesterolemia homozygote with severe atherosclerotic heart disease underwent a combined liver/heart transplantation procedure (2). Familial hypercholesterolemia is caused by a deficiency of normal LDL receptors, which retards the hepatic clearance of LDL. Postoperatively, the patient had increased hepatic clearance of LDL and only moderate hypercholesterolemia, indicating that the metabolic defect had been partially corrected by the liver transplantation (2). A patient with tyrosinemia had nearly complete correction of that defect with liver transplantation $(1,3)$, and both hemophilia $A$ and hemophilia $B$ are correctable by liver transplantation $(1,4,5)$. The extent to which inborn errors of metabolism are corrected after this procedure has frequently yielded fresh insights into the extent of the liver's role in the development of disease (1).

Our laboratory has focused on the metabolism of apolipoprotein $\mathrm{E}$ and the two $\mathrm{B}$ apolipoproteins, apoB48 and apoB100. Apolipoprotein $\mathrm{E}$ is a major protein component of VLDL (6), is a ligand for the LDL receptor, and is important for the receptor-mediated uptake of chylomicron and VLDL remnants by the liver. Apolipoprotein $\mathrm{E}$ is also found in relatively high levels in the cerebrospinal fluid (CSF), ${ }^{1}$ and investigators have speculated that it may play an important role in the redistribution of lipids within the brain (7-9). Apolipoprotein B48, which contains the amino-terminal 2,152 amino acids of apoB 100 , is a crucial structural protein in chylomicrons and is generally thought to be synthesized exclusively by the human intestine (10), although a recent report has suggested that small amounts of the protein might be made by the human liver (11). Apolipoprotein B100 is a crucial structural protein in the formation of the triglyceride-rich VLDL in the liver (12), but recent studies have suggested that the human intestine may also synthesize apoB100 $(11,13-17)$.

Studies performed over the past decade have demonstrated that there are commonly occurring polymorphisms in both the apoB and apoE genes $(6,18)$. These polymorphisms result in

1. Abbreviations used in this paper: CSF, cerebrospinal fluid; IEF, isoelectric focusing. 
amino acid substitutions and phenotypic changes in the proteins that can be assessed by simple laboratory tests. Isoelectric focusing can be used to characterize commonly occurring phenotypes of apoE that are due to substitutions involving charged amino acids at residues 112 and 158 (6). Radioimmunoassays using the apoB-specific monoclonal antibody MB19 can be used to detect the genetically determined "MB19 phenotype" in apoB48 and apoB100 (19); the MB19 polymorphism is perfectly associated with and probably caused by an amino acid substitution at apoB residue $71(20)$.

We initiated a study of the changes in apoE and apoB phenotypes after liver transplantation with the expectation that a study in those patients could provide important insights into apolipoprotein physiology. This expectation was fulfilled; the study of liver transplant patients was uniquely informative about several topics in human apolipoprotein physiology. Among the issues addressed in this study were the origin of apoE in serum and CSF, the glycosylation pattern of the serum apoE that is derived from extrahepatic sources, the origin of the apoE-A-II heterodimers, the origin of apoB48 in fasting plasma, and the origin of the apoB 100 that appears in the plasma "chylomicron fraction" after a fat-rich meal.

\section{Methods}

Study population. We obtained blood samples from 29 liver transplant recipients in the operating room on the day of their operation. Blood samples from respective organ donor patients were obtained premortem in the operating room before the organs were harvested (i.e., before life support was discontinued). We also obtained blood samples from all the postoperative recipients; these samples were obtained at least 1 mo and usually 2-6 mo after the operation. Serum and plasma (containing $1 \mathrm{mg}$ EDTA $/ \mathrm{ml}$ ) were separated from the blood cells by centrifugation at $4^{\circ} \mathrm{C}$, and the samples were frozen at $-70^{\circ} \mathrm{C}$. Genomic DNA was prepared from the white blood cells $(21) . \sim 1 \mathrm{ml}$ of CSF, which was collected by lumbar puncture for diagnostic purposes, was obtained from six patients. The studies described here were approved by the Human Experimentation Committee of the Pacific Presbyterian Medical Center.

Apolipoprotein E phenotyping. Apolipoprotein E phenotyping was performed by isoelectric focusing (IEF) (22). The most common apoE isoform is apoE3. Apolipoprotein E4, a more basic isoform, differs from apoE3 in having an arginine-for-cysteine substitution at residue 112. Apolipoprotein E2 is a more acidic isoform and is most commonly the result of a cysteine-for-arginine substitution at residue 158 (6). In the general population, there are three homozygous apoE phenotypes (E3/3, E4/4, and E2/2) and three heterozygous apoE phenotypes $(E 4 / 2, E 4 / 3$, and $E 3 / 2)$. Because different apoE isoforms distribute differently within the plasma lipoprotein fractions (23-25), we performed apoE phenotyping on whole serum samples using the Western blot IEF system reported by Menzel and Utermann (22). Only $1 \mu$ l of plasma was loaded onto each lane of the IEF gel. After electrophoresis, the proteins in the gel were electrophoretically transferred to a sheet of nitrocellulose membrane for immunoblotting. Apolipoprotein E-specific antibodies for these studies were kindly provided by Drs. L. Curtiss, K. Weisgraber, and S. Kunitake. Serum from subjects previously characterized as having the apoE3/3, apoE4/4, apoE3/2, and apoE4/3 phenotypes were included as controls on each gel. Phenotyping studies of CSF apoE were performed by using identical Western blotting techniques. However, the CSF was first concentrated by a SpeedVac Concentrator (Savant Instruments, Farmingdale, NY); the concentrated proteins from $50 \mu \mathrm{l}$ of CSF were loaded onto each lane of the gel.

Detection of disulfide-linked apolipoprotein $E$ complexes. To detect the presence of apoE-A-II heterodimers (26) and disulfide-linked apoE homodimers (27) in plasma, $1 \mu \mathrm{l}$ of plasma was mixed with $30 \mu \mathrm{l}$ of sample buffer (10 mM Tris-HCl, pH 8.0,3\% SDS) and loaded onto a $10-20 \%$ gradient SDS-polyacrylamide slab gel (28). Individual samples were loaded onto the gel both in the presence (reduced) and the absence (nonreduced) of $3 \% \beta$-mercaptoethanol. After the serum proteins were separated by electrophoresis, the samples were electrophoretically transferred to a sheet of nitrocellulose membrane for immunoblotting (28). For these studies, we used a rabbit antiserum to apoE, kindly provided by $\mathrm{K}$. Weisgraber, and a polyclonal antibody to apoA-II, kindly provided by S. Kunitake.

Phenotyping of apolipoprotein B100 with monoclonal antibody $M B 19$. The apoB-specific monoclonal antibody MB19, which was developed and characterized by Curtiss and Edgington (29), detects a commonly occurring two-allele polymorphism in apoB (19). Antibody MB19 binds to plasma apoB with three distinct patterns of immunoreactivity; strong, intermediate, or weak. These three binding patterns are the result of the codominant inheritance of two common apoB alleles that encode for apoB allotypes MB19, and MB19, which have high and low affinity, respectively, for antibody MB19. Thus, subjects with strong or weak binding patterns are homozygous for allotypes MB19, or $\mathrm{MB} 19_{2}$, respectively, whereas those with an intermediate pattern are heterozygotes. There is a perfect association between the MB19 1 allotype, the absence of an Apa LI site at apoB cDNA nucleotide 421, and isoleucine at residue 71 ; the $\mathrm{MB} 19_{2}$ allotype is associated with the presence of an Apa LI site at nucleotide 421 and threonine at residue 71. Both the change in the Apa LI site and the amino acid substitution are the result of a single nucleotide substitution in the fourth exon of the apoB gene (20). To characterize this polymorphism in liver transplant patients, we enzymatically amplified the appropriate region of the apoB gene and examined the amplified DNA for the presence of the Apa LI site, as described (20). In addition, the plasma MB19 apoB phenotype was assessed by immunoassay of plasma samples $(19,30)$. Apolipoprotein B48 is invariably present in only trace amounts, relative to the large amounts of apoB 100 , in normal plasma. This was also true for donor plasma and preoperative and postoperative recipient plasma. For practical purposes, therefore, immunoassays of plasma assess only the MB19 phenotype of the apoB100, and are not measurably influenced by the apoB48 phenotype.

We also assessed the MB19 phenotypes of LDL samples prepared by ultracentrifugation. The $\operatorname{LDL}(d=1.025-1.063 \mathrm{~g} / \mathrm{ml})$ were prepared from 15 plasma samples by standard ultracentrifugation techniques (31). These samples represented complete sets of three plasma samples (i.e., preoperative recipient plasma, donor plasma, and postoperative recipient plasma) from five donor-recipient pairs. The apoB content of each LDL sample was determined by an RIA using the apoB-specific monoclonal antibody MB3 (32). The MB3 immunoassay was calibrated by determining the protein concentration of the standard LDL by the method of Lowry et al. (33), using BSA as the standard. All of the LDL samples contained apoB100, and most had no more than trace amounts of apoA-I and apoE, as judged by Coomassie blue-stained SDS-polyacrylamide gels. Each LDL sample was tested for its MB19 binding pattern in a competitive RIA, exactly as described (19). Briefly, serial dilutions of each LDL sample, along with an LDL standard from an $\mathrm{MB19} / \mathrm{MB} 19_{1}$ homozygote, were incubated with a fixed and limiting concentration of antibody MB19 in microtiter plates that had previously been coated with the standard LDL. After an overnight incubation, the amount of bound antibody MB19 was quantitated by the addition of radioiodinated second antibody. Results of the RIA were plotted as $B / B_{0}$ versus the log of the apoB concentration of the standard or competitor added, where $B$ and $B_{0}$ are the specific counts per minute-bound in the presence and absence of competitor, respectively.

To assess the MB19 phenotype of the apoB100 and apoB48 in VLDL and "chylomicron fractions," we simultaneously determined the MB19 phenotypes of the electrophoretically separated apoB 100 and apoB48 proteins by a double-label Western blot assay (28). We studied four subjects who had undergone transplantation over 6 mo before the study and had remained clinically well and normolipidemic. $60 \mathrm{ml}$ of blood was obtained from each subject after a 14-h fast and again $2 \mathrm{~h}$ after a meal containing $80 \mathrm{~g}$ of fat. The blood was collected 
into tubes containing EDTA $(1 \mathrm{mg} / \mathrm{ml})$. The plasma was immediately separated from the blood cells by centrifugation, and protease inhibitors were added to the plasma (34). The fasting plasma samples were clear, whereas the postprandial plasma samples were turbid in all patients. The VLDL samples were prepared from the plasma samples of fasted subjects by standard ultracentrifugation techniques (31). The plasma chylomicron fraction was isolated from the postprandial plasma as previously described (28). Briefly, $15 \mathrm{ml}$ of plasma was overlaid with $15 \mathrm{ml}$ of PBS and then ultracentrifuged for $30 \mathrm{~min}$ at 23,000 rpm in a model SW28 rotor (Beckman Instruments, Inc., Fullerton, CA). In the fasting plasma, no chylomicrons were detectable at the top of the ultracentrifuge tube, but a thin, white layer of chylomicrons was visible at the top of the tubes containing postprandial plasma samples. Each chylomicron fraction was recentrifuged for $24 \mathrm{~h}$ at $39,000 \mathrm{rpm}$ in a model type 40.3 rotor (Beckman Instruments, Inc.).

To examine the MB19 phenotype of the apoB48 and apoB100, the delipidated apolipoproteins of the fasting VLDL and the postprandial chylomicron fraction were separated by $3-12 \%$ gradient SDS-PAGE under nonreducing conditions, then electrophoretically transferred to a sheet of nitrocellulose membrane for immunoblotting (28). The positions of the apoB48 and apoB100 bands on the membrane were identified by staining the membrane with Ponceau S. The nitrocellulose membrane was then simultaneously incubated with $10^{7} \mathrm{cpm}$ of ${ }^{125} \mathrm{I}$-antibody MB19/ml (to detect the polymorphism) and $10^{7} \mathrm{cpm}$ of ${ }^{131} \mathrm{I}$-antibody $\mathrm{MB} 3 / \mathrm{ml}$ (to quantitate the apoB transferred to the membrane). Labeling of immunopurified monoclonal antibodies to high specific activities $(15,000 \mathrm{cpm} / \mathrm{ng})$ was performed using the lactoperoxidase method (Enzymobeads; Bio-Rad Laboratories, Richmond, CA). After the blots were washed, autoradiography was performed. The apoB48 and apoB 100 bands were then removed from the nitrocellulose membrane and counted in a double-channel gamma counter. The ratio of ${ }^{125} \mathrm{I} /{ }^{131} \mathrm{I}$ counts in each band was calculated. Chylomicron and VLDL fractions from three different normolipidemic control subjects were included on each gel. The control subjects included an MB19, $/$ MB19 homozygote, an MB19, $/ \mathrm{MB}_{1} 9_{2}$ heterozygote, and an $\mathrm{MB} 19_{2} / \mathrm{MB} 19_{2}$ homozygote. Previously, we have demonstrated that this double-label immunoassay can be used to assess the MB19 phenotype of apoB48 and apoB100; we found that the apoB48 and the apoB100 bands of normal subjects invariably have the same MB19 phenotype (28). This double-label assay has also been shown to be useful for MB19 phenotyping even when different apoB species within a lipoprotein sample have different MB19 phenotypes, as is the case in certain subjects with hypobetalipoproteinemia (32). As indicated in Results, we invariably found apoB100 in each chylomicron fraction. To verify that the apoB 100 found in each chylomicron fraction was not an artifact resulting from contamination by LDL-sized particles, the size of the particles in the chylomicron fraction was evaluated by negative-stain electron microscopy, as described (35).

Ag phenotyping of serum. Ag phenotyping of serum was performed by the passive hemagglutination inhibition assay, using human red cells (type $\mathrm{O}, \mathrm{Rh}-$ ) coated with purified human LDL of an appropriate phenotype and human $\mathrm{Ag}$ antisera with corresponding specificities, as described in detail elsewhere (36).

To test for the presence of anti-apoB antibodies with $\mathrm{Ag}$ specificity in the postoperative serum of liver transplant patients, a direct hemagglutination assay was used. Each patient's serum was diluted 1:4 with PBS, and aliquots were incubated separately with a battery of seven red cell suspensions coated with $\mathrm{LDL}$ of different $\mathrm{Ag}$ types, covering the full spectrum of the 10 known $\mathrm{Ag}$ specificities (36). The preparation of the LDL-coated red cells and the reaction conditions were exactly the same for the Ag phenotyping discussed above, except that the human anti-Ag serum (used as reagent in the antigen test) was replaced by an equal volume of PBS (36)

Immunocytochemistry of liver and intestinal biopsy specimens. Liver biopsy specimens as well as duodenal, jejunal, and ileal biopsy specimens were obtained from eight organ donor subjects. Most of the organ donors had received only intravenous feedings for the $24 \mathrm{~h}$ before the biopsy procedure. The specimens were immediately fixed in forma- lin. After 4-12 $\mathrm{h}$ of fixation, the samples were washed in PBS and incubated overnight at $4^{\circ} \mathrm{C}$ in PBS containing $18 \%$ sucrose. The tissue was frozen in liquid nitrogen, and cryostat sections were cut, mounted on slides, and incubated in a blocking buffer before being used for immunocytochemistry. The sections were incubated with a wide range of dilutions of mouse ascites fluid containing various apoB-specific monoclonal antibodies for $24 \mathrm{~h}$, washed, and subsequently incubated with biotinylated anti-mouse IgG and then a biotinylated horseradish peroxidase complexed to avidin (Vector Laboratories, San Francisco, CA) as described (37). For these studies, we used several different apoBspecific monoclonal antibodies $(29,32)$ that bind both apoB48 and apoB100 (MB24, MB11, MB3) and two antibodies specific for the carboxyterminal portion of apoB100 (MB44 and MB43) that bind apoB100 but not apoB48. Peroxidase activity was detected with diaminobenzidine and nickel, and the sections were lightly counterstained with methyl green and then photographed.

\section{Results}

We obtained preoperative and postoperative plasma and serum specimens from 29 consecutive liver transplant recipients, and preoperative plasma and serum specimens from their respective organ donors. In three other cases, preoperative and postoperative recipient specimens were available, but no donor specimens were available. $\sim 30 \%$ of the recipients underwent liver transplantation for biliary tract disease, and $70 \%$ for parenchymal liver disease. A single recipient with Wilson's disease represented the only case of an inborn error of metabolism. The mean age of the recipients was $46 \mathrm{yr}$; only three were younger than $20 \mathrm{yr}$ of age. The mean age for the organ donor patients was 24 , with a range of 4 to $58.68 \%$ of the organ donors had sustained major trauma. Of the deaths from trauma, $65 \%$ were due to vehicular accidents. Most of the other donors died as a result of subarachnoid or intracerebral hemorrhages.

The results of the serum apoE phenotyping studies are summarized in Table I. In 11 of 26 cases, the apoE phenotype of donor serum and preoperative recipient serum was identical, so these cases were not informative. However, in 15 cases, the donor and preoperative recipient serum apoE phenotypes were different. In each of these cases, the postoperative recipient serum apoE phenotype converted to that of the donor. In two

Table I. Apolipoprotein E Phenotypes of Preoperative Recipient Serum, Donor Serum, and Postoperative Recipient Serum

\begin{tabular}{cccc}
\hline & \multicolumn{3}{c}{ ApoE phenotype } \\
\cline { 2 - 4 } No. subjects & $\begin{array}{c}\text { Preoperative } \\
\text { recipient }\end{array}$ & Donor & $\begin{array}{c}\text { Postoperative } \\
\text { recipient }\end{array}$ \\
\hline 10 & $3 / 3$ & $3 / 3$ & $3 / 3$ \\
1 & $4 / 3$ & $4 / 3$ & $4 / 3$ \\
5 & $3 / 3$ & $3 / 2$ & $3 / 2$ \\
3 & $3 / 2$ & $3 / 3$ & $3 / 3$ \\
4 & $3 / 3$ & $4 / 3$ & $4 / 3$ \\
1 & $4 / 3$ & $3 / 3$ & $3 / 3$ \\
1 & $4 / 3$ & $4 / 2$ & $4 / 2$ \\
1 & $4 / 3$ & $4 / 4$ & $4 / 4$ \\
Donor serum not available & & & \\
1 & $3 / 3$ & - & $3 / 3$ \\
1 & $4 / 4$ & - & $3 / 2$ \\
1 & $4 / 3$ & - & $3 / 2$ \\
\hline
\end{tabular}


of the three cases where no donor serum was available, a change in the recipient's postoperative apoE phenotype occurred. An example of an IEF gel showing a change in apoE phenotype after liver transplantation is shown in Fig. 1. The conversion of the recipient serum apoE phenotype to that of the donor was complete insofar as we could measure. In most cases, the apoE phenotyping system that we used was not sufficiently sensitive to detect in the postoperative recipient serum the presence of an apoE isoform made by the recipient's extrahepatic tissues but not made by the donor liver. Occasionally, however, when examining postoperative recipient serum, prolonged exposure of the autoradiogram of the isoelectric focusing gel did reveal a small amount of an apoE isoform that was present in the preoperative recipient plasma, but not made by the donor liver. For example, the preoperative apoE phenotype of one of the liver transplant recipients was 4/4. 3 mo postoperatively, the phenotype was clearly $3 / 2$, but a very faint apoE4 band was detectable (Fig. 2, lane 5). Because the half-life of apoE in plasma is only a few hours (23), and because the postoperative recipient blood samples were always taken more than 1 mo after the operation, the apoE4 band must have been due to the synthesis of apoE4 by extrahepatic tissues. In several other cases, we were able to detect a small amount of extrahepatic apoE synthesis (i.e., an apoE isoform made by extrahepatic tissues, but not the donor liver) by loading several micrograms of delipidated VLDL proteins, rather than serum, onto the IEF gel (data not shown). We estimate that the extrahepatic contribution to the serum apoE pool invariably represented significantly $<10 \%$ of the total serum apoE.

Apolipoprotein $\mathrm{E}$ is an easily detectable protein component of human and canine $\operatorname{CSF}(8,38)$. The fact that astrocytes synthesize apoE (7) strongly suggests that a portion of the apoE in CSF is produced locally in the brain. However, many serum proteins, particularly those with low molecular weight, are present in the CSF. For example, apoA-I, which has a molecular weight only slightly lower than that of apoE ( $28 \mathrm{vs.} 35 \mathrm{kD})$, is present in the CSF and appears to enter the CSF from the

\section{Apo-E}

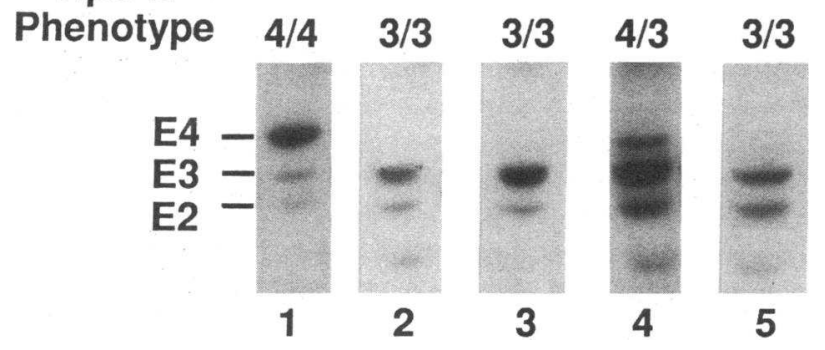

Figure 1. A Western blot of an IEF gel demonstrating the apoE isoforms in serum. Isoelectric focusing was performed according to the method of Menzel and Utermann (22). The migration positions of E4, E3, and E2 isoforms are shown on the left. The cathode is at the top, and the anode is at the bottom. (Lane 1) A serum sample from a control subject with the $4 / 4$ phenotype. (Lane 2) A serum sample from a control subject with the $3 / 3$ phenotype. (Lane 3) A serum sample from a liver transplant donor, phenotype 3/3. (Lane 4) A preoperative recipient serum sample, phenotype 4/3. (Lane 5) A postoperative serum sample from the same patient as in lane 4, phenotype $3 / 3$. Minor sialylated apoE isoforms, which have a more acidic pI, are visible in each lane below the major apoE isoforms. For example, the band in lane 1 that migrates in the $\mathrm{E} 3$ position is monosialo apoE4.

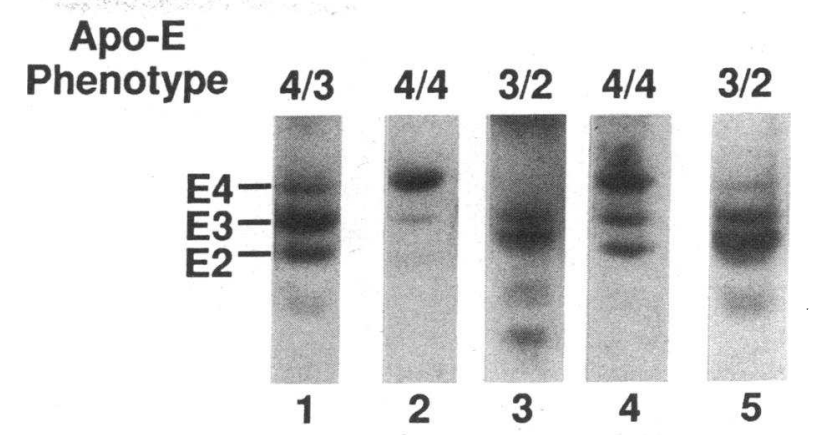

Figure 2. A Western blot of an IEF gel demonstrating the apoE isoforms in serum. The migration positions of E4, E3, and E2 are shown on the left. (Lane 1) Serum from a control subject with the $4 / 3$ phenotype. (Lane 2) Serum from a control subject, phenotype 4/4. (Lane 3) Serum from a control subject, phenotype 3/2. (Lane 4) Preoperative serum from a liver transplant recipient, phenotype 4/4. (Lane 5) Postoperative serum from the same patient as in lane 4, phenotype $3 / 2$. However, on the heavily exposed autoradiogram shown in lane 5 , a very faint $\mathrm{E} 4$ band is detectable. The apoE4 in this lane is from synthesis of apoE4 in the extrahepatic tissues of the recipient.

plasma compartment $(8,38)$. We reasoned that examining the CSF of liver transplant patients would enable us to assess whether the apoE in CSF originated mainly from the plasma pool or was produced locally. If both the serum and CSF phenotype changed after transplantation, it would suggest that the CSF apoE was derived primarily from the plasma pool. If, on the other hand, the CSF apoE phenotype did not change, it would suggest that most of the apoE was made locally. Our studies on the CSF of liver transplant patients indicated that most of the apoE in CSF is made locally (Table II). The six CSF samples that we obtained from liver transplant patients were sterile and had normal protein and glucose concentrations. Studies in two subjects (subjects 1 and 2 in Table II) were not informative because the apoE phenotype of the preoperative recipient serum and that of the donor serum were identical. However, studies in four other patients (subjects 3-6 in Table II) demonstrated a difference between the apoE phenotype of the postoperative serum and that of the CSF. For example, postoperatively, the serum apoE phenotype of subject 6 was $3 / 2$, but the CSF apoE phenotype was $4 / 3$ (Fig. 3, lanes 4 and 5 ), the same as this subject's preoperative serum phenotype. Similarly, in subject 4 , the serum apoE phenotype converted from $4 / 3$ to $4 / 2$ postoperatively (Fig. 4 , lanes 4 and 5 ), but the CSF phenotype remained $4 / 3$ (Fig. 4 , lane 6 ).

Table II. Cerebrospinal Fluid Apolipoprotein E Phenotype after Liver Transplantation

\begin{tabular}{ccccc}
\hline Subject & $\begin{array}{c}\text { Preoperative } \\
\text { recipient } \\
\text { serum }\end{array}$ & $\begin{array}{c}\text { Donor } \\
\text { serum }\end{array}$ & $\begin{array}{c}\text { Postoperative } \\
\text { recipient } \\
\text { serum }\end{array}$ & $\begin{array}{c}\text { Postoperative } \\
\text { recipient } \\
\text { CSF }\end{array}$ \\
\hline 1 & $3 / 3$ & $3 / 3$ & $3 / 3$ & $3 / 3$ \\
2 & $3 / 3$ & $3 / 3$ & $3 / 3$ & $3 / 3$ \\
3 & $3 / 3$ & $3 / 2$ & $3 / 2$ & $3 / 3$ \\
4 & $4 / 3$ & $4 / 2$ & $4 / 2$ & $4 / 3$ \\
5 & $3 / 3$ & $4 / 3$ & $4 / 3$ & $3 / 3$ \\
6 & NA & NA & $3 / 2$ & $4 / 3$ \\
\hline
\end{tabular}


Apo-E

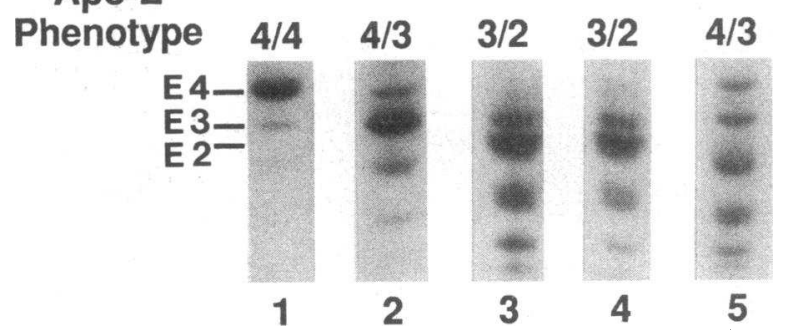

Figure 3. A Western blot of an IEF gel demonstrating the apoE isoforms in serum and CSF. (Lane 1) Serum from a control subject, phenotype 4/4. (Lane 2) Serum from a control subject, phenotype 4/3. (Lane 3) Serum from a control subject, phenotype 3/2. (Lane 4) Postoperative serum from liver transplant recipient 6 (see Table II), phenotype 3/2. (Lane 5) Postoperative CSF from the same recipient as in lane 4, phenotype 4/3. The apoE from CSF is more heavily sialylated than plasma apoE, which accounts for the increased amount of immunoreactive material below the major apoE isoforms (towart the anode). A large proportion of CSF apoE migrated more slowly on SDS-polyacrylamide gels, compared with serum apoE (data not shown). This characteristic of CSF apoE, which is due to a heavier sialylation, has been previously noted and characterized by Pitas et al. (8). :

Two of the liver transplant recipients were particularly interesting because they involved subjects with the 4/4 phenotype. Apolipoprotein $\mathrm{E} 4$ contains no cysteine residues and therefore cannot participate in either the formation of apoE-A-II heterodimers (25) or apoE homodimers (27). One liver transplant recipient, who had serum apoE phenotype $4 / 4$ preoperatively, converted to phenotype $3 / 2$ postoperatively. No apoE-A-II or apoE dimers were present in the serum preoperatively (Fig. 5 , lane 2), but both were easily detectable in the postoperative

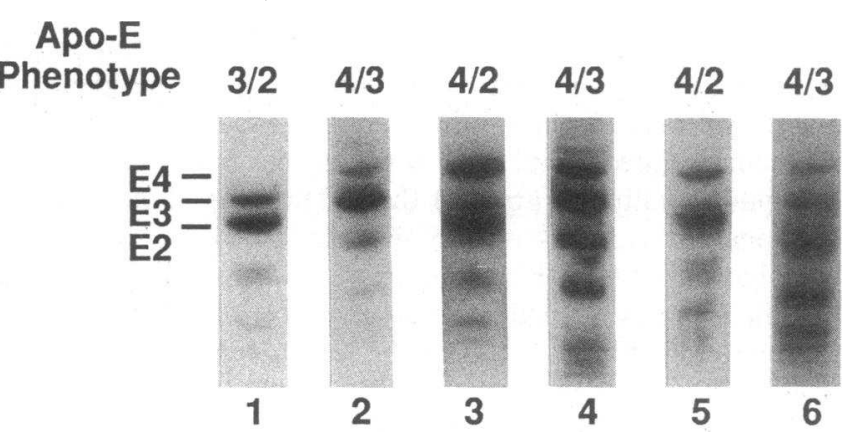

Figure 4. A Western blot of an IEF gel demonstrating the apoE isoforms in serum and CSF. (Lane 1) Serum from a control subject, phenotype 3/2. (Lane 2) Serum from a control subject, phenotype 4/3. (Lane 3) Serum from a liver transplant donor, phenotype $4 / 2$. (Lane 4) Preoperative serum from a liver transplant recipient (recipient 4 in Table II), phenotype 4/3. (Lane 5) Postoperative serum from the same recipient as in lane 4, phenotype 4/2. (Lane 6) Postoperative CSF from the same recipient, phenotype 4/3. Fig. 3 illustrates that the apoE in CSF is more heavily sialylated and contains more minor acidic isoforms than plasma apoE. Fortunately, with this IEF system, serum apoE2 focuses at a distinctively more basic position than monosialo E3 (compare lanes 3 and 5). The monosialo E3 band in the CSF (lane 6) focuses more acidically than asialo apoE2. Thus, if a significant amount of asialo apoE2 were present in the CSF of recipient 4 , it would have been detectable above the monosialo E3 band (lane 6).

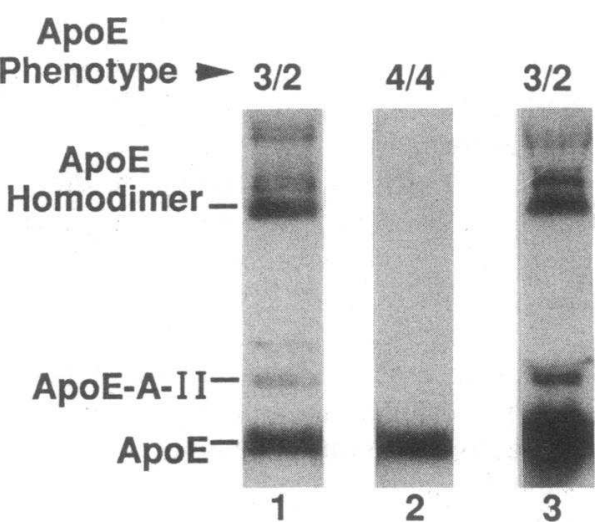

Figure 5. Apolipoprotein E immunoblots of nonreduced serum samples electrophoresed on an SDS-polyacrylamide gel. $1 \mathrm{ml}$ of serum was mixed with $30 \mu \mathrm{l}$ of a sample buffer that contained no reducing agents and was loaded onto a 10-20\% gradient SDS-polyacrylamide slab gel. After electrophoresis, the separated proteins were electrophoretically transferred to a sheet of nitrocellulose membrane for immunoblotting with an apoE-specific antibody. (Lane 1 ) Serum from a control subject, phenotype 3/2. (Lane 2) Preoperative serum from a liver recipient, phenotype 4/4. (Lane 3) Postoperative serum from the same recipient, phenotype $3 / 2$. The isoelectric focusing gels for the three serum samples shown in this figure are shown in lanes 3-5 of Fig. 2. No apoE-A-II heterodimers or apoE homodimers were observed when the samples were incubated with $2 \% \cdot \beta$-mercaptoethanol before electrophoresis on the SDS-polyacrylamide gel (data not shown). The apparent molecular weight of the apoE-A-II was exactly the same in lanes 1 and 3 (see Fig. 6). This was also the case for the apoE homodimer. The minor bands above the apoE homodimer band in lanes 1 and 3 represent various oligomers that are possible because apoE 2 contains two cysteine residues (compare with Fig. 6 , lanes 1 and 3, where no apoE2 exists). The identity of the apoE-A-II complex was confirmed with immunoblots using an apoA-II specific antibody (data not shown).

serum (Fig. 5, lane 3), indicating that hepatic apoE participates in disulfide-linked complexes with apoA-II and with itself (Fig. 5). Another subject had phenotype $4 / 3$ preoperatively and received a liver from a donor with the $4 / 4$ phenotype. Immunoblots of the donor serum revealed the complete absence of apoE-A-II heterodimers and apoE homodimers (Fig. 6, lane 1). The recipient serum, obtained 6 mo postoperatively, had a typical 4/4 phenotype, as judged by the immunoblot-IEF gel technique. On immunoblots of SDS-polyacrylamide gels that were performed under nonreducing conditions, apoE-A-II heterodimers and apoE homodimers were visible in the postoperative recipient serum (Fig. 6, lane 3), although they were at least 10 -fold fainter, relative to the intensity of the apoE monomer, than the dimer bands in preoperative recipient serum (Fig. 6, lane 2). Because the donor liver synthesized only apoE4, which cannot participate in dimer formation, the observed dimers must have involved the apoE3 synthesized by extrahepatic tissues. These studies indicate that extrahepatic apoE can participate in disulfide-linked dimer formation. Interestingly, in the latter recipient, both the apoE-A-II heterodimers and the apoE homodimers in the postoperative serum had a slightly higher apparent molecular weight compared with those in the preoperative sample (Fig. 6, lane 2 vs. lane 3). The higher molecular weight of these disulfide-linked apoE complexes, compared with those found in the preoperative sample and other control samples, was also observed in two subsequent experiments. 


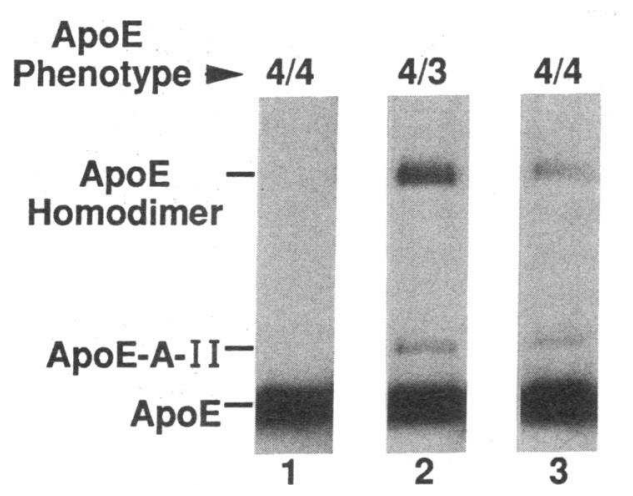

Figure 6. Apolipoprotein E immunoblots of nonreduced serum samples electrophoresed on a 10-20\% gradient SDS-polyacrylamide gel. See legend to Fig. 5 for conditions. (Lane 1) Serum from the donor, phenotype 4/4, as assessed by isoelectric focusing. (Lane 2) Preoperative serum of the liver transplant recipient, phenotype 4/3. (Lane 3) Serum from the same recipient obtained 6 mo postoperatively. By isoelectric focusing, this serum sample had a typical 4/4 phenotype. The slightly higher migration of the apoE-A-II heterodimer and the apoE homodimers in the postoperative serum (lane 3), compared with the preoperative serum (lane 2), was a consistent finding in multiple experiments. The higher migration of the dimers was not observed after the serum was treated with neuraminidase (data not shown).

The slower migration of these disulfide-linked complexes in the postoperative serum was eliminated by neuraminidase treatment of the serum (data not shown). This finding suggests that the serum apoE that is produced in extrahepatic tissues is more heavily glycosylated than the serum apoE that is derived from the liver.

The MB19 phenotype of the apoB100 in plasma was assessed by RIA using the apoB-specific antibody MB19. Because apoB48 is present in only trace amounts in the plasma, relative to apoB100, RIAs of plasma samples assess only the apoB 100 phenotype. The MB19 phenotype of the apoB 100 in postoperative recipient plasma converted to the phenotype of the donor in all four subjects studied (Table III). Competitive RIAs that demonstrate changes in the MB19 phenotype of LDL samples are shown in Fig. 7.

Prior studies have proven that allotypes MB19 ${ }_{1}$ and $\mathrm{MB} 19_{2}$ can be detected by human antisera specific for the $\mathrm{Ag}(\mathrm{c})$ and $\mathrm{Ag}(\mathrm{g})$ epitopes, respectively (39). The latter two epitopes represent two of 10 different $\mathrm{Ag}$ epitopes that can be detected using antisera from multiply transfused thalassemic patients (36). All 10 antisera were used to analyze the changes in apoB 100 phenotype in 15 liver transplant patients. We found that the postoperative recipient apoB phenotype, as judged by all 10 markers, was invariably identical to that of the donor (Table IV). Because many liver transplant recipients were exposed to new Ag antigens produced by the donor liver, we tested whether any of the 15 liver transplant recipients had developed antibodies specific for the foreign $\mathrm{Ag}$ allotypes produced by the donor liver. However, we did not detect any Ag-specific antibodies in any of the postoperative recipient serum samples, each of which was taken more than 3 mo postoperatively.

To determine whether the MB19 phenotypes of apoB48 changed after liver transplantation, we used a double-label Western blot immunoassay $(28,32)$. We obtained plasma from four liver transplant recipients after they had fasted for $14 \mathrm{~h}$,
Table III. The MB19 Phenotype of the Preoperative Recipient, Donor, and Postoperative Recipient Plasma Apolipoprotein B100 from 28 Liver Transplant Operations

\begin{tabular}{cccc}
\hline & \multicolumn{3}{c}{ MB19 phenotype } \\
\cline { 2 - 4 } No. subjects & $\begin{array}{c}\text { Preoperative } \\
\text { recipient }\end{array}$ & Donor & $\begin{array}{c}\text { Postoperative } \\
\text { recipient }\end{array}$ \\
\hline 8 & $2 / 2$ & $2 / 2$ & $2 / 2$ \\
1 & $1 / 2$ & $1 / 2$ & $1 / 2$ \\
8 & $1 / 2$ & $2 / 2$ & $2 / 2$ \\
7 & $2 / 2$ & $1 / 2$ & $1 / 2$ \\
3 & $1 / 1$ & $1 / 2$ & $1 / 2$ \\
1 & $1 / 2$ & $1 / 1$ & $1 / 1$ \\
\hline
\end{tabular}

Phenotyping of plasma samples was performed by determining their MB19 binding pattern by radioimmunoassay (17). Allotype 1 (MB19) has a high affinity for antibody MB19; allotype 2 (MB19) has a low affinity for antibody MB19. Plasmas yielding a weak pattern of immunoreactivity with antibody MB19 have phenotype 2/2; an intermediate pattern, phenotype $1 / 2$; a strong pattern, phenotype $1 / 1$ (17). The MB19 phenotype of the preoperative recipient plasma and the donor plasma correlated perfectly with those predicted from an Apa LI digestion of an apoB gene fragment amplified from the genomic DNA of these subjects (18). The 28 complete sets of plasma samples (pre- and postoperative recipient samples and donor sample) shown in this table include the 26 sets of plasma samples shown in Table I, plus a complete set of samples from two other liver transplant operations not included in the original 29. The postoperative apoB phenotypes were, in each case, unequivocal. The assays revealed no evidence of a small amount of contamination from the preoperative MB19 phenotype such as would occur if there were a significant amount of extrahepatic synthesis of apoB 100 . The assay that we used is sufficiently sensitive to detect easily a $5-10 \%$ extrahepatic synthesis of an $\mathrm{MB} 19_{1} / \mathrm{MB} 19_{2} \mathrm{LDL}$ in a subject who had received a liver from an $\mathrm{MB} 19_{2} / \mathrm{MB} 19_{2}$ donor.

then prepared the VLDL by ultracentrifugation. The apoB 100 and apoB48 were separated from the other VLDL apolipoproteins by SDS-PAGE. Examination of the postoperative VLDL samples from four normolipidemic liver transplant patients confirmed that the phenotype of the apoB 100 converted to that of the donor liver (Table V). In contrast, the postoperative MB19 phenotype of the apoB48 was invariably the same as that of the preoperative plasma of the recipient and did not change to the phenotype of the donor (Table V).

We then evaluated the "chylomicrons" that were isolated from plasma obtained from the same four subjects $2 \mathrm{~h}$ after a fat-rich meal. (None of the subjects had detectable chylomicrons under fasting conditions.) Examination of the postprandial chylomicrons by Coomassie blue-stained SDS-polyacrylamide slab gels revealed that the apoB 100 band stained slightly more intensely than the apoB48 band (data not shown). This finding was in keeping with the results that we previously observed in normolipidemic control subjects (28). To exclude the possibility that the apoB 100 in this fraction was an artifact resulting from contamination by particles of the LDL size range, we examined each of the chylomicron preparations by negative-stain electron microscopy. The lipoproteins were heterogeneous in size, with most particles having a diameter of 350-1,500 nm. Particles in the LDL size range $(<250 \mathrm{~nm})$ were infrequent $(5-10 \%)$. The MB19 phenotypes of the apoB100 and the apoB48 in the chylomicron fractions were 


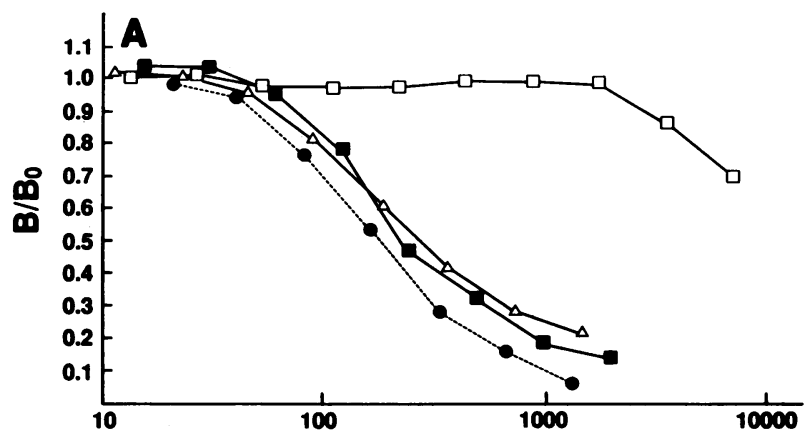

Table IV. Ag Phenotypes of the Liver Donor, Preoperative Recipient, and Postoperative Recipient Serum
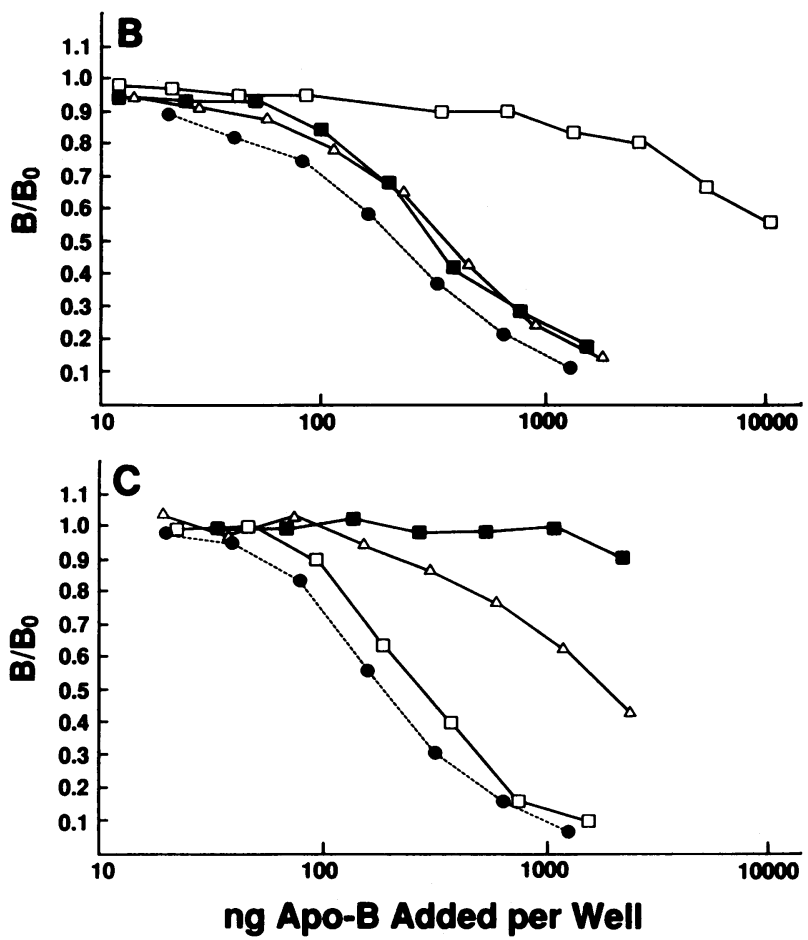

Figure 7. Competitive RIAs demonstrating a change in the MB19 phenotype of LDL samples that were prepared from plasma of liver transplant donors and recipients. The results of each assay are plotted as $B / B_{0}$ vs. $\log$ of the apoB protein added per well, where $B$ and $B_{0}$ represent specific counts bound in the presence and absence of competitor, respectively. In each panel, $(\bullet \cdots \bullet)$ represents a control LDL with a "strong" MB19 binding pattern, or the $\mathrm{MB} 19_{1} / \mathrm{MB} 19_{1}$ phenotype. This control LDL was isolated by ultracentrifugation from the plasma of a laboratory employee. In each panel, $(\square-\square)$ represents the LDL of the preoperative recipient LDL; $(-\square)$, postoperative recipient LDL; $(\Delta-\Delta)$, donor LDL. In $A$ and $B$, the donor phenotype was $\mathrm{MB} 19_{1} / \mathrm{MB} 19_{2}$ (an "intermediate" binding pattern, the result of an equal concentration of apoB allotypes $\mathrm{MB} 19_{1}$ and $\mathrm{MB} 19_{2}$ ) and the preoperative recipient phenotypes were $\mathrm{MB} 19_{2} / \mathrm{MB} 19_{2}(\mathrm{a}$ "weak" binding pattern). The phenotype of the recipient's postoperative LDL was MB19, MB19. Low density lipoproteins having phenotype $\mathrm{MB1} 9_{1} / \mathrm{MB} 19_{2}$ are displaced approximately twofold to the right, compared with the phenotype MB19, $/ \mathrm{MB} 19_{1}$ standard LDL (see reference 19). In $C$, the donor phenotype was $\mathrm{MB} 19_{2} / \mathrm{MB} 19_{2}$; the pre- and postoperative recipient phenotypes were $\mathrm{MB} 19_{1} / \mathrm{MB} 19_{2}$ and $\mathrm{MB} 19_{2} / \mathrm{MB} 19_{2}$, respectively. An Apa LI digestion of an apoB gene fragment amplified from the genomic DNA (20) of the donor shown in $C$ predicted that the donor plasma would have phenotype $\mathrm{MB} 19_{2} / \mathrm{MB} 19_{2}$ by immunoassay. The immunoassay shown in $C$ supports this prediction, although the pattern of immunoreactivity is slightly stronger than usually seen with LDL samples with phenotype $\mathrm{MB} 19_{2} / \mathrm{MB} 19_{2}$. That is, the donor LDL competition curve is shifted

\begin{tabular}{|c|c|c|c|c|c|c|c|c|c|c|}
\hline \multirow[b]{2}{*}{ Subject } & \multicolumn{10}{|c|}{$\mathbf{A g}$} \\
\hline & $x$ & $\mathbf{y}$ & $a_{1}$ & d & c & $\mathrm{g}$ & $t$ & $\mathrm{z}$ & h & $\mathrm{i}$ \\
\hline $\mathbf{R} \mathbf{1}$ & + & - & + & - & - & + & + & - & - & + \\
\hline D1 & - & + & + & + & - & + & + & - & - & + \\
\hline R1 F/U & - & + & + & + & - & + & + & - & - & + \\
\hline $\mathbf{R} 2$ & + & + & + & + & + & + & + & - & + & + \\
\hline D2 & + & + & - & + & + & - & + & - & - & + \\
\hline $\mathrm{R} 2 \mathrm{~F} / \mathrm{U}$ & + & + & - & + & + & - & + & - & - & + \\
\hline R3 & + & + & + & + & + & + & + & - & - & + \\
\hline D3 & - & + & + & + & - & + & + & + & - & + \\
\hline R3 F/U & - & + & + & + & - & + & + & + & - & + \\
\hline R4 & + & + & + & + & - & + & + & + & - & + \\
\hline D4 & - & + & - & + & + & + & + & - & - & + \\
\hline R4 F/U & - & + & - & + & + & + & + & - & - & + \\
\hline R5 & + & + & + & + & - & + & + & + & + & + \\
\hline D5 & - & + & + & + & + & + & + & - & - & + \\
\hline R5 F/U & - & + & + & + & + & + & + & - & - & + \\
\hline R6 & - & + & - & + & + & + & + & - & - & + \\
\hline D6 & - & + & - & + & + & + & + & + & + & + \\
\hline R6 F/U & - & + & - & + & + & + & + & + & + & + \\
\hline R7 & - & + & + & + & - & + & + & + & - & + \\
\hline D7 & - & + & - & + & + & + & + & - & + & + \\
\hline R7 F/U & - & + & - & + & + & + & + & - & + & + \\
\hline R8 & + & + & + & + & + & + & + & + & - & + \\
\hline D8 & + & + & + & - & - & + & + & - & - & + \\
\hline R8 F/U & + & + & + & - & - & + & + & - & - & + \\
\hline R9 & - & + & + & + & - & + & + & - & - & + \\
\hline D9 & - & + & + & + & + & + & + & + & - & + \\
\hline R9 F/U & - & + & + & + & + & + & + & + & - & + \\
\hline
\end{tabular}

The presence $(+)$ or absence $(-)$ of 10 different $\mathrm{Ag}$ antigens was assessed in the donor, preoperative recipient, and postoperative recipient serum according to published techniques (34). Donors are designated D1-D9; preoperative recipients are designated R1-R9; postoperative recipients are designated R1 F/U-R9 F/U. Shown here are results from 9 of 15 liver transplantation operations that were assessed by $\mathrm{Ag}$ phenotyping. In all 15 liver transplantation operations that were assessed, the $\mathrm{Ag}$ phenotype of the liver transplant recipient converted to that of the donor.

examined by the double-label Western blot assay. In each of the four recipients, the MB19 phenotype of the apoB100 was identical to the MB19 phenotype of the donor liver, whereas the MB19 phenotype of the apoB48 was identical to that present in the preoperative plasma of the recipient (Table VI). These data indicate that the vast majority of the apoB 100 that appears in the plasma chylomicron fraction after a fat-rich meal is of hepatic, not intestinal, origin.

Our results with the ${ }^{125} \mathrm{I} /{ }^{131} \mathrm{I}$ Western blot assay indicate that the large majority of apoB48 is made in the intestine and that the large majority of apoB100 (even the apoB 100 in the

somewhat to the left, compared with the curves usually observed with LDL samples having the MB19 $/ \mathrm{MB} 19_{2}$. This observation is most likely explained by the fact that the donor in $C$ had received $10 \mathrm{U}$ of plasma or whole blood within $12 \mathrm{~h}$ of the liver-harvesting operation, at which time the blood sample was obtained. 
Table V. The MB19 Phenotype of Apolipoprotein B100 and Apolipoprotein B48 in the Postoperative VLDL Fraction of Four Liver Transplant Recipients, as Assessed by a Double-Label Western Blot Assay

\begin{tabular}{|c|c|c|c|c|c|c|}
\hline & \multicolumn{4}{|c|}{ Plasma radioimmunoassay: MB19 phenotype of the plasma apoB 100} & \multicolumn{2}{|c|}{$\begin{array}{l}\text { Double-label Western blot assay: Ratio } \\
\text { of }{ }^{125} \mathrm{I}-\mathrm{MB} 19 \mathrm{cpm} \text { to }{ }^{131} \mathrm{I}-\mathrm{MB} 3 \mathrm{cpm}\end{array}$} \\
\hline & $\begin{array}{l}\text { Control } \\
\text { subjects }\end{array}$ & $\begin{array}{l}\text { Preoperative } \\
\text { recipient }\end{array}$ & Donor & $\begin{array}{l}\text { Postoperative } \\
\text { recipient }\end{array}$ & ApoB100 & ApoB48 \\
\hline Expe & & & & · & & \\
\hline \multicolumn{7}{|c|}{ Control subjects } \\
\hline 1 & $1 / 1$ & - & - & - & 6.8 & 6.6 \\
\hline 2 & $1 / 2$ & - & - & - & 4.0 & 3.8 \\
\hline 3 & $2 / 2$ & - & - & - & 1.2 & 1.8 \\
\hline \multicolumn{7}{|c|}{$\begin{array}{l}\text { Liver transplant } \\
\text { recipients }\end{array}$} \\
\hline 1 & - & $1 / 2$ & $2 / 2$ & $2 / 2$ & $1.2(2 / 2)^{*}$ & $4.2(1 / 2)^{*}$ \\
\hline 2 & - & $1 / 2$ & $2 / 2$ & $2 / 2$ & $1.4(2 / 2)$ & $4.7(1 / 2)$ \\
\hline \multicolumn{7}{|c|}{ Experiment 2} \\
\hline \multicolumn{7}{|c|}{ Controls } \\
\hline 1 & $1 / 1$ & - & - & - & 4.3 & 4.3 \\
\hline 2 & $1 / 2$ & - & - & - & 2.9 & 2.3 \\
\hline 3 & $2 / 2$ & - & - & - & 1.2 & 1.0 \\
\hline \multicolumn{7}{|c|}{$\begin{array}{l}\text { Liver transplant } \\
\text { recipients }\end{array}$} \\
\hline 2 & - & $1 / 2$ & $2 / 2$ & $2 / 2$ & $0.8(2 / 2)^{*}$ & $3.0(1 / 2)^{*}$ \\
\hline 3 & - & $2 / 2$ & $1 / 2$ & $1 / 2$ & $3.1(1 / 2)$ & $1.2(2 / 2)$ \\
\hline 4 & - & $2 / 2$ & $1 / 2$ & $1 / 2$ & $2.9(1 / 2)$ & $0.9(2 / 2)$ \\
\hline
\end{tabular}

Shown on the left side of this table are the MB19 apoB100 phenotypes of each subject studied. The MB19 phenotype of the plasma apoB100 was assessed by RIA of plasma, exactly as previously described (17) (see Methods). Shown on the right side are the results of the double-label Western blot assay of the apoB100 and apoB48 in the VLDL fraction. The VLDL fractions were prepared by ultracentrifugation from the plasma of four postoperative normolipidemic liver transplant patients and control subjects. Each plasma sample was obtained after a $14 \mathrm{~h}$ fast. ${ }^{*}$ The MB19 phenotype of the apoB100 and apoB48 bands of the postoperative liver transplant recipients' VLDL is shown in parentheses. The MB19 phenotype of these bands was determined by comparing the ${ }^{125} \mathrm{I} /{ }^{131} \mathrm{I}$ ratios in the apoB48 and apoB 100 bands with those observed in control subjects.

Table VI. The MB19 Phenotype of Apolipoprotein B100 and Apolipoprotein B48 in the Postoperative Chylomicron Fraction of Four Liver Transplant Recipients, as Assessed by a Double-Label Western Blot Assay

\begin{tabular}{|c|c|c|c|c|c|c|}
\hline & \multicolumn{4}{|c|}{ Plasma radioimmunoassay: MB19 phenotype of the plasma apoB100 } & \multirow{2}{*}{\multicolumn{2}{|c|}{$\begin{array}{l}\text { Double-label Western blot assay: Ratic } \\
\text { of }{ }^{125} \mathrm{I}-\mathrm{MB} 19 \mathrm{cpm} \text { to }{ }^{131} \mathrm{I}-\mathrm{MB} 3 \mathrm{cpm}\end{array}$}} \\
\hline & \multirow{2}{*}{$\begin{array}{l}\text { Control } \\
\text { subjects }\end{array}$} & \multirow{2}{*}{$\begin{array}{l}\text { Preoperative } \\
\text { recipient }\end{array}$} & \multirow[b]{2}{*}{ Donor } & \multirow{2}{*}{$\begin{array}{l}\text { Postoperative } \\
\text { recipient }\end{array}$} & & \\
\hline & & & & & ApoB 100 & ApoB48 \\
\hline \multicolumn{7}{|c|}{ Control subjects } \\
\hline 1 & $1 / 1$ & - & - & - & 6.4 & 6.7 \\
\hline 2 & $1 / 2$ & - & - & - & 4.7 & 4.5 \\
\hline 3 & $2 / 2$ & - & - & - & 1.3 & 1.0 \\
\hline \multicolumn{7}{|c|}{$\begin{array}{l}\text { Liver transplant } \\
\text { recipients }\end{array}$} \\
\hline 1 & - & $1 / 2$ & $2 / 2$ & $2 / 2$ & $1.0(2 / 2)^{*}$ & $5.5(1 / 2)^{*}$ \\
\hline 2 & - & $1 / 2$ & $2 / 2$ & $2 / 2$ & $0.9(2 / 2)$ & $5.5(1 / 2)$ \\
\hline 3 & - & $2 / 2$ & $1 / 2$ & $1 / 2$ & $5.8(1 / 2)$ & $1.6(2 / 2)$ \\
\hline 4 & - & $2 / 2$ & $1 / 2$ & $1 / 2$ & $5.2(1 / 2)$ & $1.1(2 / 2)$ \\
\hline
\end{tabular}

Shown on the left side of this table are the MB19 apoB100 phenotypes of each subject studied. The MB19 phenotype of the plasma apoB100 was assessed by RIA of plasma (17) (see Methods). Shown on the right side are the results from the double-label Western blot assay of the apoB100 and apoB48 in the chylomicron fractions. The chylomicrons were prepared by ultracentrifugation from the plasma of postoperative liver transplant patients. The plasma samples were obtained $2 \mathrm{~h}$ after a fat-rich meal (see Methods). Liver transplant recipients $1-4$ in this table are identical to recipients 1-4 in Table V. * The MB19 phenotype of the apoB100 and apoB48 bands of the postoperative liver transplant recipients' chylomicrons are shown in parentheses. The MB19 phenotype of these bands was determined by comparing the ${ }^{125} \mathrm{I} /{ }^{131} \mathrm{I}$ ratios in the apoB48 and apoB100 bands with those observed in control subjects. 
"chylomicron fraction") is made in the liver. However, it is important to add a cautionary statement regarding the sensitivity of the ${ }^{125} \mathrm{I} /{ }^{131} \mathrm{I}$ Western blot MB19 phenotyping assay. This assay system is probably not sufficiently sensitive to detect a $5 \%$ hepatic contribution to the apoB48 pool or a 5\% intestinal contribution to the apoB100 pool. However, control LDL and postprandial VLDL mixing experiments (data not shown) have indicated that the Western blot assay is capable of detecting a $15 \%$ contribution of the liver to the apoB48 pool or a $15 \%$ contribution of the intestine to the apoB 100 pool.

To examine directly the possibility of apoB100 synthesis by the intestine, we used immunocytochemical techniques to examine the duodenal, jejunal, and ileal biopsy specimens as well as liver biopsy specimens from eight organ donors. Monoclonal antibodies that bind to the amino-terminal portion of apoB100 (MB3, MB11, and MB24) bound strongly to the liver biopsy specimens as well as to all of the intestinal biopsy specimens. Antibodies binding to the carboxy-terminal portion of apoB100 (MB43 and MB44) bound to the apoB in hepatocytes. These latter antibodies detected apoB 100 in the vascular submucosa of the intestinal enterocytes; however, even when the carboxy-terminal antibodies were incubated with the biopsy specimens at high concentrations, no specific staining of intestinal enterocytes was observed. Examples of our immunocytochemical studies are shown in Fig. 8.

\section{Discussion}

Plasma and serum samples were collected from liver transplant donors and recipients because we were convinced that the study of these samples would yield unique insights into apolipoprotein physiology. One of the questions that we wanted to address was the proportion of serum apoE that was synthesized in the liver versus extrahepatic tissues. Prior studies had demonstrated that apoE was synthesized in a wide variety of extrahepatic tissues and cells, including kidney, adrenal, skeletal muscle, monocyte-macrophages, and the central and peripheral nervous systems (40-47). We believed that we could address the issue of the proportion of serum apoE that originates in the liver by examining the postoperative serum of liver transplant patients who had received a liver from a subject with a different apoE phenotype. This idea was not unique to our group; just months after we began to collect samples for our study, Kraft et al. reported a retrospective study of changes in apoE, apoA-IV, and $\mathrm{Lp}(\mathrm{a})$ phenotypes in 18 liver transplant patients (48). $\mathrm{Al}$ though donor serum was unavailable for most of the cases examined by these investigators, they nevertheless demonstrated convincingly that the serum apoE phenotype frequently changes after liver transplantation. Our study, performed on donor and recipient serum samples collected in a prospective fashion, confirmed this finding. We found that the postopera-
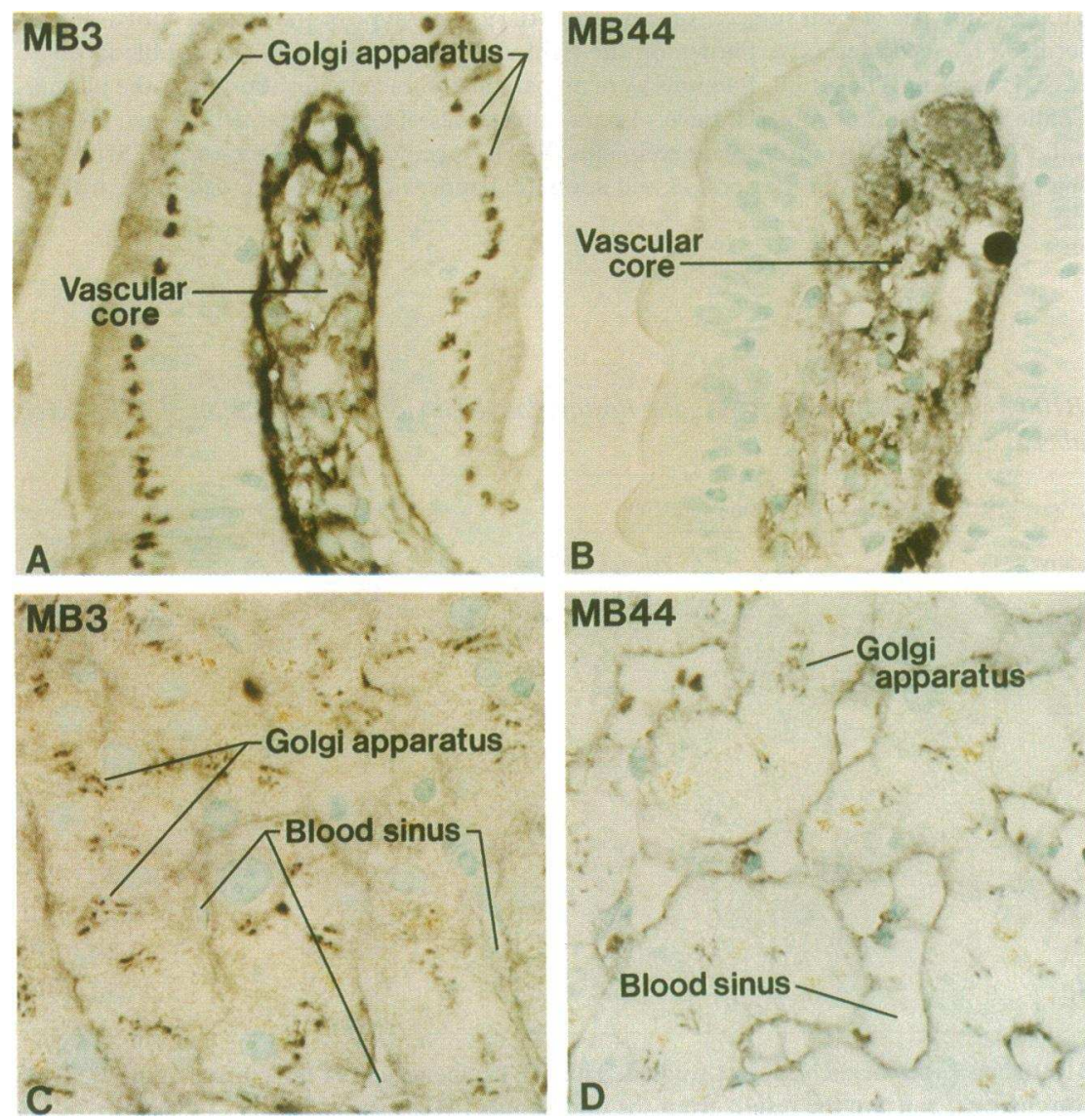

Figure 8. Binding of two apoB-specific monoclonal antibodies, MB3 and MB44, to liver and duodenal biopsy specimens from an organ donor. The epitope for antibody MB3, which binds to both apoB100 and apoB48 (29), is located between apoB100 amino acids 994 and 1084 (59); the epitope for MB44, which binds to apoB100 but not apoB48 (34), is located between apoB 100 amino acids 2488 and 2658 (59). $(A)$ The binding of MB3 to a duodenal biopsy specimen; $(B)$ the binding of MB44 to a duodenal biopsy specimen; $(C)$ the binding of $\mathrm{MB} 3$ to a liver biopsy specimen; $(D)$ the binding of MB44 to a liver biopsy specimen. For the biopsy specimens shown in each panel, a dilute solution of the apoB-specific monoclonal antibody (1/ 20,000 dilution of ascites fluid for MB3 and a 1/1,000 dilution of ascites fluid for MB44) was incubated with the tissue samples. MB3 binds strongly to the Golgi apparatus of intestinal epithelial cells (but not to the mucus-secreting cells). It also binds to the Golgi apparatus of liver parenchymal cells. Binding is also present in the vascular core of the intestinal villi and along the blood sinuses of the liver. MB44 binds to the Golgi apparatus of liver parenchymal cells; it binds to the vascular intestinal villi core, but not to intestinal epithelial cells. With two other monoclonal antibodies that bind to the amino-terminal portion of apoB100 (MB11 and MB24), we obtained results identical to those shown here with antibody MB3. One other antibody binding to the carboxy-terminal portion of apoB100 (MB43) yielded results identical to those shown with antibody MB44. In parallel

experiments, we were unable to demonstrate binding of either antibodies MB43 or MB44 to intestinal enterocytes when applied to those biopsy specimens in high concentrations (1/50 dilution of ascites fluid). Duodenal biopsy specimens are shown in panel $A$ and $B$; we were also unable to detect apoB 100 in the jejunal and ileal biopsy specimens. 
tive serum apoE phenotype of the recipient not only changes, but invariably converts to that of the donor (Table I). The change in serum apoE phenotype, as judged by IEF gels, was almost always complete; we occasionally found evidence for an isoform synthesized by extrahepatic tissues of the recipient (Fig. 2). We agree with the conclusion of Kraft et al. (48) that at least $90 \%$ of the serum apoE is synthesized by the liver. By investigating apoE mRNA levels in a variety of tissues of nonhuman primates, Newman et al. (46) concluded that from 20 to $40 \%$ of apoE may be synthesized extrahepatically in these species. It remains conceivable that $20-40 \%$ of apoE $i$ s synthesized in extrahepatic tissues in humans but, because of local catabolism of the protein, this relatively high degree of extrahepatic synthesis is not reflected in the serum apoE pool.

Roheim and co-workers pointed out in 1979 that relatively high levels of apoE are present in normal human CSF (38). They recognized two possible ways that apolipoproteins could enter the CSF: through local production and then diffusion into the CSF or through crossing the blood-brain barrier from the plasma, as is the case for certain other serum proteins. Subsequent studies demonstrated that brain tissue $(43,44)$, and specifically the astrocytic glia of the brain (7), synthesizes apoE. Pitas et al. (8) recently characterized the apolipoproteins and lipoproteins of human and canine CSF, and, like the earlier studies of Roheim et al. (38), they found that apoE was present in a relatively high concentration in CSF. They also found that CSF apoE was more heavily sialylated than plasma apoE (8). These facts suggested that at least a portion of the apoE in CSF is produced locally. Our study on the CSF of liver transplant patients addressed the issue of the origin of CSF apoE in a novel way: by examining the CSF of four liver transplant patients in whom we had observed a virtually complete change in serum apoE phenotype. We found that the CSF apoE phenotype did not change to the phenotype of the donor liver, implying that the majority of CSF apoE must be synthesized locally (Table II).

Weisgraber and Mahley reported in 1978 that human apoE can form disulfide-linked heterodimers with apoA-II (26). They demonstrated that these heterodimers are present in the plasma lipoproteins and are not an artifact produced during the preparation of plasma lipoproteins. Apolipoprotein E4 cannot participate in apoE-A-II formation because it lacks a cysteine residue (25). Recently, Weisgraber and Shinto have demonstrated that apoE3 and apoE2, but not apoE4, can form disulfide-linked homodimers $(27,48 a)$. In this study, we were able to demonstrate that both hepatic apoE and extrahepatic apoE can participate in the formation of these disulfide-linked complexes (Figs. 5 and 6). In their original description of apoEA-II heterodimers, Mahley and Weisgraber pointed out that uncertainty remained about whether this disulfide-linked complex was formed in the plasma or was formed intracellularly and secreted directly from cells (26). Our experiments demonstrating the participation of extrahepatic apoE in apoE-A-II formation support the former possibility. Although both apoE and apoA-II are synthesized in extrahepatic tissues, they are synthesized in different extrahepatic tissues. The extrahepatic synthesis of apoA-II occurs primarily in intestinal enterocytes (49), a tissue that makes little or no apoE $(6,44,50)$.

Apolipoprotein $\mathrm{E}$ is known to be posttranslationally glycosylated at threonine 194 (51). In human serum, only $\sim 20 \%$ of the apoE is glycosylated (51). There is some evidence that the apoE produced by some extrahepatic tissue culture cells, such as astrocytes and monocyte-macrophages, is more extensively glycosylated than the apoE in serum $(47,52)$. However, it has remained unclear whether the apoE in serum that originates in extrahepatic tissues has a distinct glycosylation pattern, compared with the bulk of the serum apoE, which originates in the liver. Data presented in this study suggest that the apoE in serum that originates in extrahepatic tissues may indeed have a distinct glycosylation pattern. We examined a liver transplant recipient (preoperative phenotype $4 / 3$ ) who received a liver from a donor with the $4 / 4$ phenotype. Postoperatively, the serum apoE phenotype had a typical 4/4 pattern, as judged by IEF. Nevertheless, there were very small amounts of apoE-A-II heterodimers and apoE homodimers in his plasma; because apoE4 cannot participate in dimer formation $(25,27)$, these dimers must have contained apoE3 produced by extrahepatic tissues. Both disulfide-linked complexes in the postoperative serum were of a slightly higher apparent molecular weight, compared with the dimers found in the preoperative serum. However, the size difference disappeared after neuraminidase treatment of the postoperative serum. These findings strongly imply that extrahepatic apoE is more heavily glycosylated than hepatic apoE, and that the different glycosylation pattern persists in the circulation. If the carbohydrate of extrahepatic apoE were processed in the circulation (either enzymatically or nonenzymatically) so that the glycosylation pattern conformed to the glycosylation pattern observed for the bulk of serum apoE, one would not expect to observe the higher apparent molecular weight of the disulfide-linked complexes containing extrahepatic apoE.

We also studied changes in the phenotype of apoB 100 after liver transplantation, both by immunoassays using the allotype-specific monoclonal antibody MB19 and immunoassays using Ag-specific antisera. Using the MB19 immunoassays, we demonstrated in 28 liver transplant patients that the apoB100 phenotype invariably changes completely to that of the donor (Table III). This finding, which was confirmed by $\mathrm{Ag}$ phenotyping studies (Table IV), is in keeping with the generally accepted notion that the liver synthesizes the vast majority of apoB 100 in human plasma $(12,53)$. The Ag-specific antibodies that we used for apoB phenotyping were derived from the serum of multiply transfused thalassemic patients. We tested the hypothesis that some liver transplant recipients might make antibodies to novel $\mathrm{Ag}$ antigens synthesized by the donor liver; however, no such antibodies were detectable, perhaps because of the therapeutic immunosuppression regimen prescribed for liver transplant recipients.

Apolipoprotein B48 is synthesized in the intestine as a result of the editing of a single nucleotide of the apoB mRNA, which creates a premature stop codon $(54,55)$. The editing process in humans is developmentally regulated; in organ cultures, fetal intestine synthesizes primarily apoB 100 , whereas adult intestine synthesizes primarily apoB48 (56). Kane et al. (10) have demonstrated that apoB48 is virtually the only apoB species in chyle, obtained from thoracic duct drainage, clearly implicating the intestine as a major contributor to the apoB48 observed in triglyceride-rich lipoproteins after a fat-rich meal. Recently, however, Higuchi et al. (11) have reported that a very small percentage of human hepatic apoB cDNA clones have the edited nucleotide, raising the possibility that the human liver might synthesize small amounts of apoB48. If a small percentage of the liver's apoB synthesis were apoB48, it would not be unreasonable to hypothesize that, given the large mass 
of hepatic tissue, a significant fraction of the apo-B48 in fasting plasma could be derived from the liver. To address directly the question of the tissue origin of the apoB48 in fasting plasma, we simultaneously determined the MB19 phenotype of the apoB48 and apoB100 in the fasting VLDL of four normolipidemic liver transplant patients using a double-label Western blot assay $(28,32)$. Each patient had received a liver from a donor with a different MB19 phenotype. We demonstrated that the MB19 phenotype of the apoB100 in fasting VLDL changed to the phenotype of the donor. However, it was equally clear that the apoB48 phenotype did not change (Table $\mathrm{V})$, demonstrating that the liver is not a significant source of apoB48 in fasting plasma. It is important to point out that our conclusions are based upon the analysis of a small number of patients, and it remains conceivable that the liver could make a contribution to apoB48 synthesis in some individuals.

Our MB19 phenotyping studies on the postprandial plasma chylomicron fraction of liver transplant patients were quite informative. First, these studies confirmed that the apoB48 present in the buoyant lipoproteins after a meal is synthesized by the intestine; if there were a hepatic contribution to postprandial apoB48 production in humans, it would have to be quite small. Second, and equally interesting, we found that the apoB 100 that is contained within the chylomicron fraction is of hepatic origin. Previously, the fact that the large, triglyceriderich lipoproteins in postprandial plasma contained a significant amount of apoB 100 had suggested to some investigators the possibility that the intestine might synthesize some apoB100. Recently, Cohn and co-workers reported that the apoB100 content of human VLDL rapidly increases after a fat-rich meal; however, these investigators were unable to be certain about the origin of this apoB 100 (57). Our data in liver transplant patients show that the apoB 100 in the postprandial plasma "chylomicron fraction" is derived from the liver. Our finding is consistent with the hypothesis that the human liver rapidly secretes large, buoyant, triglyceride-rich apoB100-containing lipoproteins into the plasma in response to the uptake of the remnant lipoproteins of intestinal origin $(57,58)$.

Our genetic evidence that the apoB 100 in the plasma chylomicron fraction is of hepatic origin (Table VI) is consistent with the results of our immunocytochemistry studies (Fig. 8). Using several monoclonal antibodies that bind to apoB 100 but not apoB48, we were unable to detect apoB100 in the intestinal enterocytes of organ donors. In contrast to our results, Davidson et al. (15), Hoeg et al. (16), and Levy et al. (17) recently reported small amounts of apoB100 synthesis by normal human intestinal biopsy specimens in metabolic labeling studies. Also, Dullaart et al. (13), Hoeg et al. (16), and Levy et al. (17) have reported immunocytochemical evidence for apoB 100 synthesis in normal intestinal biopsy specimens. The reason for the discrepancy between their findings and ours is not clear. We did not do any metabolic labeling studies on biopsy specimens. In our immunochemical studies, we used different (but nevertheless thoroughly characterized) apoB-specific monoclonal antibodies. One possibility that might explain the discrepant findings is that our immunochemical studies were not sufficiently sensitive to detect small amounts of apoB 100 in the intestinal biopsy specimens. However, it is noteworthy that we were unable to detect apoB100 in the intestinal mucosal cells even when the intestinal biopsy specimens were incubated with very high concentrations of several different apoB100-specific antibodies; with dilute concentrations of these antibodies, we could detect apoB100 in the liver as well as in the submucosal tissues of the intestine. Another possibility is that there may be a significant natural variation in the amount of apoB 100 production by enterocytes of different individuals; it is possible that the intestinal enterocytes of our adult organ donors, unlike the normal subjects studied by other investigators $(13,16,17)$, simply did not make apoB 100 . It is conceivable that the adult human intestine responds to the stress of hospitalization, life support measures, and treatment of major trauma or a cerebrovascular accident (a virtually universal situation with organ donors) by reducing or "shutting off" the very low level synthesis of apoB100 that occurs under normal conditions.

\section{Acknowledgments}

We would like to acknowledge M. Hardiman for technical assistance, K. Weisgraber, S. Kunitake, and L. Curtiss for apoE-specific antibodies, L. Curtiss and J. Witztum for apoB-specific monoclonal antibodies, W. Concepcion and P. Nakagato for help in obtaining serum and plasma samples from donors and recipients, M. Macawile and J. Lim for processing of blood and tissue samples, T. Gridley for manuscript preparation, C. Benedict and T. Rolain for graphics, and A. Averbach and S. Seehafer for editorial assistance.

Supported by grants from the National Institutes of Health (HL01672 and HL-41633) and a Syntex Scholars Award to S. G. Young. J. K. Boyles is an Established Investigator of the American Heart Association. M. F. Linton is the recipient of a fellowship award from the American Heart Association, California Affiliate.

\section{References}

1. Starzl, T. E., A. J. Demetris, and D. V. Thiel. 1989. Liver transplantation. N. Engl. J. Med. 321:1014-1022 and 1092-1099.

2. Bilheimer, D. W., J. L. Goldstein, S. M. Grundy, T. E. Starzl, and M. S. Brown. 1984. Liver transplantation to provide low-density lipoprotein receptors and lower plasma cholesterol in a child with homozygous familial hypercholesterolemia. N. Engl. J. Med. 311:1658-1664.

3. Starzl, T. E., B. J. Zitelli, B. W. Shaw, Jr., S. Iwatsuki, J. C. Gartner, R. D. Gordon, J. J. Malatack, I. J. Fox, A. H. Urbach, and D. H. V. Thiel. 1985. Changing concepts: liver replacement for hereditary tyrosinemia and hepatoma. J. Pediatr. 106:604-606.

4. Lewis, J. H., F. A. Bontempo, J. A. Spero, M. V. Ragni, and T. E. Starzl. 1985. Liver transplantation in a hemophiliac. N. Engl. J. Med. 312:1189-1190.

5. Merion, R. M., R. E. Delius, D. A. Campbell, Jr., and J. G. Turcotte. 1988. Orthotopic liver transplantation totally corrects factor IX deficiency in hemophilia B. Surgery (St. Louis). 104:929-931.

6. Mahley, R. W., and S. C. Rall, Jr. 1989. The Metabolic Basis of Inherited Disease. 6th Ed. C. R. Scriver, A. L. Beaudet, W. S. Sly, and D. Valle, editors. McGraw-Hill Book Co., New York. 1195-1213.

7. Boyles, J. K., R. E. Pitas, E. Wilson, R. W. Mahley, and J. M. Taylor. 1985. Apolipoprotein $\mathrm{E}$ associated with astrocytic glia of the central nervous system and with nonmyelinating glia of the peripheral nervous system. J. Clin. Invest. 76:1501-1513.

8. Pitas, R. E., J. K. Boyles, S. H. Lee, D. Y. Hui, and K. H. Weisgraber. 1987. Lipoproteins and their receptors in the central nervous system: characterization of the lipoproteins in cerebrospinal fluid and identification of apolipoprotein B,E(LDL) receptors in the brain. J. Biol. Chem. 262:14352-14360.

9. Mahley, R. W., J. K. Boyles, and R. E. Pitas. 1989. High Density Lipoproteins and Atherosclerosis II. N. E. Miller, editor. Elsevier Science Publishers, Amsterdam. 263-268.

10. Kane, J. P., D. A. Hardman, and H. E. Paulus. 1980. Heterogeneity of apolipoprotein B: isolation of a new species from human chylomicrons. Proc. Natl. Acad. Sci. USA. 77:2465-2469.

11. Higuchi, K., A. V. Hospattankar, S. W. Law, N. Meglin, J. Cortright, and H. B. Brewer, Jr. 1988. Human apolipoprotein B (apoB) mRNA: identification of two distinct apoB mRNAs, an mRNA with the apoB-100 sequence and an apoB mRNA containing a premature in-frame translational stop codon, in both liver and intestine. Proc. Natl. Acad. Sci. USA. 85:1772-1776.

12. Havel, R. J., and J. P. Kane. 1989. The Metabolic Basis of Inherited Disease. 6th ed. C. R. Scriver, A. L. Beaudet, W. S. Sly, and D. Valle, editors. McGraw-Hill Book Co., New York. 1129-1138. 
13. Dullaart, R. P. F., B. Speelberg, H. J. Schuurman, R. W. Milne, L. M Havekes, Y. L. Marcel, H. J. Geuze, M. M. Hulshof, and D. W. Erkelens. 1986 Epitopes of apolipoprotein B-100 and B-48 in both liver and intestine. Expression and evidence for local synthesis in recessive abetalipoproteinemia. J. Clin. Invest. 78:1397-1404.

14. Sasak, V. W., K. A. Colburn, J. S. Lown, J. B. Moberly, and J. M. Ordovas. 1989. Apolipoprotein B synthesis in the human small intestine and colon. Circulation. 80(Suppl. II):454. (Abstr.)

15. Davidson, N. O., B. Teng, and M. Verp. 1990. Human apolipoprotein B100 mRNA editing is developmentally regulated and detectable in tissues othe than small intestine. Clin. Res. 38:444A. (Abstr.)

16. Hoeg, J. M., D. D. Sviridov, G. E. Tennyson, S. J. Demosky, Jr., M. S Meng, D. Bojanovski, I. G. Safonova, V. S. Repin, M. B. Kuberger, V. N. Smirnov, K. Higuchi, R. E. Gregg, and H. B. Brewer, Jr. 1990. Both apolipoprotein B-48 and B-100 are synthesized and secreted by the human intestine. J. Lipid Res. 31:1761-1769.

17. Levy, E., C. Rochette, I. Londono, C. C. Roy, R. W. Milne, Y. L. Marcel, and M. Bendayan. 1990. Apolipoprotein B-100: immunolocalization and synthesis in human intestinal mucosa. J. Lipid Res. 31:1937-1946.

18. Young, S. G. 1990. Recent progress in understanding apolipoprotein B. Circulation. 82:1574-1594.

19. Young, S. G., S. J. Bertics, L. K. Curtiss, D. C. Casal, and J. L. Witztum 1986. Monoclonal antibody MB19 detects genetic polymorphism in human apolipoprotein B. Proc. Natl. Acad. Sci. USA. 83:1101-1105.

20. Young, S. G., and S. T. Hubl. 1989. An ApaLI restriction site polymorphism is associated with the MB19 polymorphism in apolipoprotein B. J. Lipid Res. 30:443-449.

21. Davis, L. G., M. D. Dibner, and J. F. Battey. 1986. Basic Methods in Molecular Biology. Elsevier Science Publishing Co., New York. 44-46.

22. Menzel, H. J., and G. Utermann. 1986. Apolipoprotein E phenotyping from serum by Western blotting. Electrophoresis. 7:492-495.

23. Gregg, R. E., L. A. Zech, E. J. Schaefer, D. Stark, D. Wilson, and H. B. Brewer, Jr. 1986. Abnormal in vivo metabolism of apolipoprotein $E_{4}$ in humans. J. Clin. Invest. 78:815-821.

24. Steinmetz, A., C. Jakobs, S. Motzny, and H. Kaffarnik. 1989. Differentia distribution of apolipoprotein $\mathrm{E}$ isoforms in human plasma lipoproteins. Arterio sclerosis. 9:405-411.

25. Weisgraber, K. H. 1990. Apolipoprotein E distribution among human plasma lipoproteins: role of the cysteine-arginine interchange at residue $112 . J$. Lipid Res. 31:1503-1511.

26. Weisgraber, K. H., and R. W. Mahley. 1978. Apoprotein (E-A-II) complex of human plasma lipoproteins. I. Characterization of this mixed disulfide and its identification in a high density lipoprotein subfraction. J. Biol. Chem. 253:62816288

27. Weisgraber, K. H., and L. H. Shinto. 1990. Presence of disulfide-linked apolipoprotein E-3 homodimer in human plasma and its impact on receptorbinding activity. Arteriosclerosis. 10:770a. (Abstr.)

28. Young, S. G., S. J. Bertics, T. M. Scott, B. W. Dubois, L. K. Curtiss, and J. L. Witztum. 1986. Parallel expression of the MB19 genetic polymorphism in apoprotein B-100 and apoprotein B-48. Evidence that both apoproteins are products of the same gene. J. Biol. Chem. 261:2995-2998.

29. Curtiss, L. K., and T. S. Edgington. 1982. Immunochemical heterogeneity of human plasma apolipoprotein B. I. Apolipoprotein B binding of mouse hybridoma antibodies. J. Biol. Chem. 257:15213-15221.

30. Young, S. G., S. J. Bertics, T. M. Scott, B. W. Dubois, W. F. Beltz, L. K. Curtiss, and J. L. Witztum. 1987. Apolipoprotein B allotypes MB19, and MB19, in subjects with coronary artery disease and hypercholesterolemia. Arteriosclerosis. 7:61-65.

31. Havel, R. J., H. A. Eder, and J. H. Bragdon. 1955. The distribution and chemical composition of ultracentrifugally separated lipoproteins in human serum. J. Clin. Invest. 34:1345-1353.

32. Young, S. G., S. J. Bertics, L. K. Curtiss, B. W. Dubois, and J. L. Witztum. 1987. Genetic analysis of a kindred with familial hypobetalipoproteinemia. Evidence for two separate gene defects: one associated with an abnormal apolipoprotein B species, apolipoprotein B-37; and a second associated with low plasma concentrations of apolipoprotein B-100. J. Clin. Invest. 79:1842-1851.

33. Lowry, O. H., N. J. Rosebrough, A. L. Farr, and R. J. Randall. 1951. Protein measurement with the folin phenol reagent. J. Biol. Chem 193:265-275.

34. Young, S. G., S. J. Bertics, L. K. Curtiss, and J. L. Witztum. 1987. Characterization of an abnormal species of apolipoprotein B, apolipoprotein B-37, associated with familial hypobetalipoproteinemia. J. Clin. Invest. 79:1831-1841.

35. Young S. G., F. P. Peralta, B. W. Dubois, L. K. Curtiss, J. K. Boyles, and J. L. Witztum. 1987. Lipoprotein B37, a naturally occurring lipoprotein containing the amino-terminal portion of apolipoprotein B100, does not bind to the apolipoprotein B,E (low density lipoprotein) receptor. J. Biol. Chem. 262:16604 16611 .

36. Bütler, R. 1990. Advances in Forensic Science. Vol. 3. DNA and Other Polymorphisms in Forensic Sciences. H. C. Lee, and R. E. Gaensslen, editors Yearbook Medical Publishers, Chicago. 135-159.
37. Boyles, J. K., C. D. Zoellner, L. J. Anderson, L. M. Kosik, R. E. Pitas, K. H. Weisgraber, D. Y. Hui, R. W. Mahley, P. J. Gebicke-Haerter, M. J. Ignatius, and E. M. Shooter. 1989. A role for apolipoprotein E, apolipoprotein A-I, and low density lipoprotein receptors in cholesterol transport during regeneration and remyelination of the rat sciatic nerve. J. Clin. Invest. 83:1015-1031.

38. Roheim, P. S., M. Carey, T. Forte, and G. L. Vega. 1979. Apolipoproteins in human cerebrospinal fluid. Proc. Natl. Acad. Sci. USA. 76:4646-4649.

39. Tikkanen, M. J., C. Ehnholm, P. T. Kovanen, R. Bütler, S. G. Young, K. Curtiss, and J. L. Witztum. 1987. Detection of two apolipoprotein B species (apo $\mathrm{B}_{\mathrm{c}}$ and $\mathrm{B}_{z}$ ) by a monoclonal antibody. Atherosclerosis. 65:247-256.

40. Lin-Lee, Y. C., F. T. Kao, P. Cheung, and L. Chan. 1985. Apolipoprotein $E$ gene mapping and expression: localization of the structural gene to human chromosome 19 and expression of apoE mRNA in lipoprotein- and non-lipoprotein-producing tissues. Biochemistry. 24:3751-3756.

41. Williams, D. L., P. A. Dawson, T. C. Newman, and L. L. Rudel. 1985. Apolipoprotein E synthesis in peripheral tissues of nonhuman primates. J. Biol. Chem. 260:2444-2451.

42. Driscoll, D. M., and G. S. Getz. 1984. Extrahepatic synthesis of apolipoprotein E. J. Lipid Res. 25:1368-1379.

43. Lin, C. T., Y. Xu, J. Y. Wu, and L. Chan. 1986. Immunoreactive apolipoprotein $\mathrm{E}$ is a widely distributed cellular protein. Immunohistochemical localization of apolipoprotein E in baboon tissues. J. Clin. Invest. 78:947-958.

44. Elshourbagy, N. A., W. S. Liao, R. W. Mahley, and J. M. Taylor. 1985. Apolipoprotein E mRNA is abundant in the brain and adrenals, as well as in the liver, and is present in other peripheral tissues of rats and marmosets. Proc. Natl. Acad. Sci. USA. 82:203-207.

45. Blue, M. L., D. L. Williams, S. Zucker, S. A. Khan, and C. B. Blum. 1983. Apolipoprotein E synthesis in human kidney, adrenal gland, and liver. Proc. Natl. Acad. Sci. USA. 80:283-287.

46. Newman, T. C., P. A. Dawson, L. L. Rudel, and D. L. Williams. 1985 Quantitation of apolipoprotein E mRNA in the liver and peripheral tissues of nonhuman primates. J. Biol. Chem. 260:2452-2457.

47. Basu, S. K., Y. K. Ho, M. S. Brown, D. W. Bilheimer, R. G. W. Anderson and J. L. Goldstein. 1982. Biochemical and genetic studies of the apoprotein E secreted by mouse macrophages and human monocytes. J. Biol. Chem. 257:9788-9795.

48. Kraft, H. G., H. J. Menzel, F. Hoppichler, W. Vogel, and G. Utermann. 1989. Changes of genetic apolipoprotein phenotypes caused by liver transplantation. Implications for apolipoprotein synthesis. J. Clin. Invest. 83:137-142.

48a. Weisgraber, K. H., and L. Shinto. 1991. Identification of the disulfidelinked homodimer of apolipoprotein E3 in plasma: impact on receptor-binding activity. J. Biol. Chem. In press.

49. Hussain, M. M., and V. I. Zannis. 1990. Intracellular modification of human apolipoprotein AII (apoAII) and sites of apoAII mRNA synthesis: comparison of apoAII with apoCII and apoCIII isoproteins. Biochemistry. 29:209217.

50. Rachmilewitz, D., J. J. Albers, D. R. Saunders, and M. Fainaru. 1978 Apoprotein synthesis by human duodenojejunal mucosa. Gastroenterology. 75:677-682.

51. Wernette-Hammond, M. E., S. J. Lauer, A. Corsini, D. Walker, J. M. Taylor, and S. C. Rall, Jr. 1989. Glycosylation of human apolipoprotein E. The carbohydrate attachment site is threonine 194. J. Biol. Chem. 264:9094-9101.

52. Pitas, R. E., J. K. Boyles, S. H. Lee, D. Foss, and R. W. Mahley. 1987. Astrocytes synthesize apolipoprotein E and metabolize apolipoprotein E-containing lipoproteins. Biochim. Biophys. Acta. 917:148-161.

53. Gotto, A. M., Jr. H. J. Pownall, and R. J. Havel. 1986. Introduction to plasma lipoproteins. Methods Enzymol. 128:3-41.

54. Chen, S. H., G. Habib, C. Y. Yang, Z. W. Gu, B. R. Lee, S. A. Weng, S. R Silberman, S. J. Cai, J. P. Deslypere, M Rosseneu, A M. Gotto, Jr, W. H. Li, and L. Chan. 1987. Apolipoprotein B-48 is the product of a messenger RNA with an organ-specific in-frame stop codon. Science (Wash. DC). 238:363-366.

55. Powell, L. M. S. C. Wallis, R. J. Pease, Y. H. Edwards, T. J. Knott, and J. Scott. 1987. A novel form of tissue-specific RNA processing produces apolipoprotein-B48 in intestine. Cell. 50:831-840.

56. Glickman, R. M., M. Rogers, and J. N. Glickman. 1986. Apolipoprotein B synthesis by human liver and intestine in vitro. Proc. Natl. Acad. Sci. USA. 83:5296-5300.

57. Cohn, J. S., J. R McNamara, S. D. Cohn, J. M. Ordovas, and E. J. Schaefer. 1988. Plasma apolipoprotein changes in the triglyceride-rich lipoprotein fraction of human subjects fed a fat-rich meal. J. Lipid Res. 29:925-936.

58. Craig, W. Y., R. Nutik, and A. D. Cooper. 1988. Regulation of apoprotein synthesis and secretion in the human hepatoma Hep G2. The effect of exogenous lipoprotein. J. Biol. Chem. 263:13880-13890.

59. Milne, R, R. Théolis, Jr, R Maurice, R. J. Pease, P. K. Weech, E. Rassart, J. C. Fruchart, J. Scott, and Y. L. Marcel. 1989. The use of monoclonal antibodies to localize the low density lipoprotein receptor-binding domain of apolipoprotein B. J. Biol. Chem. 264:19754-19760. 